\title{
L'étude des gènes permettra-t-elle de percer le secret de l'origine des Polynésiens?
}

Depuis que le Capitaine James Cook a atteint le Pacifique Sud en 1769, la ressemblance entre les habitants d'îles aussi éloignées que Hawaï, Tahiti et la Nouvelle-Zélande a toujours été un mystère. Cette similitude impliquait un ancêtre commun et déjà James King, l'astronome de Cook, se demandait "de quel continent ces hommes avaient-ils originellement émigré et par quelles étapes s'étaient-ils disséminés dans un espace si vaste". L'hypothèse la plus vraisemblable jusqu'à ce jour était celle du Sud-Est asiatique. Il existe des preuves archéologiques et linguistiques qui indiquent que des hommes du Sud-Est asiatique, dans une des plus grandes migrations jamais rapportées dans la préhistoire, ont traversé des milliers de kilomètres d'océan sur des embarcations primitives. Ces intrépides marins auraient quitté le Sud-Est asiatique il y a 3600 ans, dépassant sans se mêler les Mélanésiens qui s'étaient arrêtés aux berges de l'océan, en Nouvelle-GuinéePapouasie et en Australie 30000 ans auparavant. Mais maintenant, des généticiens qui ont étudié les gènes des Polynésiens actuels, ainsi que ceux de leurs ancêtres à l'aide d'ossements, pensent que cette hypothèse n'est pas totalement exacte. Ils estiment en effet que des Mélanésiens, les ancêtres des aborigènes d'Australie et des montagnards de Nouvelle-Guinée, ont peuplé la Polynésie avec les Asiatiques.

\section{Ils venaient de l'Est}

La culture Lapita fait référence à une entité archéologique et linguistique caractéristique de la Polynésie environ 3500 ans au Vanuatu, en Nouvelle-Calédonie, dans les îles Fidji et d'autres îles à l'est de l'Australie. Les archéologues ont trouvé des restes d'une société agricole qui qui est apparue soudainement voici utilisait des poteries décorées et des hameçons taillés dans l'os, vivait dans des maisons de bois dans des villages côtiers, élevait des porcs, des poulets et des chiens et portait des ornements en coquillages et obsidienne. Une culture proche, mais non identique, était présente durant le néolithique, il y a 6000 ans, à Formose et dans le sud de la Chine. Cette culture Lapita n'a jamais été trouvée en Nouvelle-Guinée ni en Australie. De même, les langues parlées par les Polynésiens sont assez proches, ce qui implique une langue ancestrale commune. Par exemple, mata signifie oeil, et ono six aussi bien en Fidjien, en Samoen et en Rapanui. Les ressemblances s'étendent aux langues parlées à Formose, aux Philippines et en Indonésie, mais pas aux langages papous parlés par les Mélanésiens. Les premières analyses génétiques faites au début des années 1980 ont semblé conforter le modèle d'un peuplement de la Polynésie uniquement par les marins du Sud-Est asiatique. En effet, une séquence de neuf paires de bases $(\mathrm{pb})$ de la région non codante de l'ADN mitochondrial (ADNmt) a été retrouvée chez les Caucasiens et les Mélanésiens mais elle était absente chez les Polynésiens et certains Asiatiques. Toutefois, ces observations reposaient sur un petit nombre d'individus et, quand les analyses furent plus nombreuses, il devint évident que, si la majorité des Polynésiens possédaient la délétion de neuf $\mathrm{pb}$, un nombre non négligeable $(5 \%)$ avait un type différent d'ADNmt nommé " cluster II ».

\section{Une nouvelle interprétation}

Or, il se trouve que ce type de séquence (cluster II) est répandu chez les Mélanésiens. Ainsi donc les Mélanésiens se seraient mêlés aux Asiatiques du Sud-Est. Mais la ques- tion clé se pose alors: avant ou après la grande migration? Un argument pour l'hypothèse précoce vient de l'analyse d'ADNmt à partir d'ossements humains trouvés dans des sites de culture Lapita aux Fidji et à Tonga, datant de 2700 à 300 ans. Les os récents possèdent la délétion de neuf pb type asiatique/polynésienne, alors que les plus anciens sont de type "cluster II". Ainsi donc les premiers habitants de ces îles seraient des Mélanésiens. Un marqueur génétique d'ADN nucléaire, les haplotypes du gène $\alpha$ globine, confirme également une part d'origine mélanésienne chez les habitants des îles du Pacifique. En effet, si $70 \%$ des Polynésiens possèdent les haplotypes la et IIa provenant d'Asie du Sud-Est, $30 \%$ ont les haplotypes IIIa, IVa et Vc, caractéristiques de la Nouvelle-GuinéePapouasie et de Vanuatu. On pourrait imaginer qu'une vague tardive d'immigrants, probablement du SudEst asiatique, aurait acquis les haplotypes IIIa, IVa et Vc alors qu'ils se mélangeaient avec les Mélanésiens au niveau de Vanuatu sur leur chemin vers la Polynésie.

La notion que les Mélanésiens seraient arrivés en Polynésie les premiers n'est qu'une pure spéculation mais l'idée qu'ils soient arrivés au moins en même temps que les Asiatiques commence à être acceptée tablement étudier plus de gènes nucléaires, et notamment ceux du chromosome $\mathrm{Y}$, pour espérer percer définitivement le secret de ces incroyables navigateurs. Il n'en reste pas moins qu'il s'agit d'une histoire extraordinaire, même si, à ce jour, le conte a encore deux fins possibles. par les généticiens. Il faut incontes-
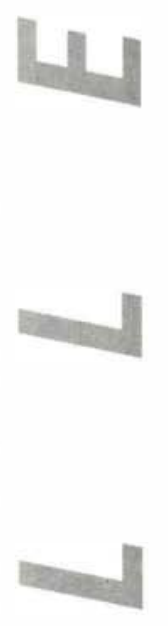

$\mathrm{m} / \mathrm{s} n^{\circ} 4$ vol. 10, avril 94
Gibbons A. Genes point to a new identify for pacific pioneers. Science 1994; 263: 32-3.

E.D.
$\begin{aligned} & \text { Gibbons A. Genes point to a new identify for } \\ & \text { pacific pioneers. Science } 1994 ; 263: 32-3 .\end{aligned}$

